\title{
Effect of almond $x$ peach hybrid rootstocks on fruit quality parameters and yield characteristics of peach cultivars
}

\author{
C. Font i Forcada, Y. Gogorcena and M.A. Moreno \\ Department of Pomology \\ Estación Experimental de Aula Dei (CSIC) \\ Consejo Superior de Investigaciones Científicas \\ Apdo. 13034, 50080 Zaragoza \\ Spain
}

Keywords: Prunus persica, sugars, firmness, vitamin C, antioxidant capacity, vigour

\begin{abstract}
The influence of six rootstocks ('Adafuel', 'Adarcias', 'Cadaman', 'Felinem' 'Garnem' and 'GF 677') on trunk cross-sectional area (TCSA), yield efficiency, and fruit quality parameters of peach cultivars [Prunus persica (L.) Batsch] was evaluated. The six rootstocks were grafted with 'Tebana' peach and 'Queen Giant' nectarine cultivars during the summer of 1997, and trees were established in a trial during the winter of 1998-1999. The experiment was located in the Ebro Valley (Zaragoza, Spain), on a heavy and calcareous soil. The fruit quality parameters (fruit weight, firmness, soluble solids, $\mathrm{pH}$, titratable acidity, and ripening index) and phytochemical constituents (vitamin $\mathrm{C}$, phenol, flavonoid and anthocyanin contents, and relative antioxidant capacity) were determined. In addition, the most important sugars found in fruit flesh (sucrose, glucose, fructose and sorbitol) were analyzed by High Performance Liquid Chromatography (HPLC).

At the eleventh year after grafting, the lowest vigour was induced by 'Adarcias' rootstock with both varieties, although differences were not significant with 'Cadaman' when grafted with 'Queen Giant'. For this cultivar, yield efficiency was higher on 'Cadaman' rootstock, although differences were not significant with 'Felinem'. In the case of 'Tebana, no significant differences among rootstocks were found. Regarding fruit quality parameters, the greatest soluble solids content (SSC) was recorded on 'Adarcias' and 'Cadaman' and the lowest on 'GF 677', while no significant differences were found among all the other rootstocks, in the case of 'Queen Giant'. With this cultivar, the highest firmness was also induced by 'Cadaman' and the lowest by 'GF 677' whereas significant differences were not found among the other rootstocks. The highest titratable acidity (TA) was induced by 'Cadaman', although this did not differ significantly from 'Adafuel' when grafted with 'Queen Giant'. The highest vitamin C content was shown on 'Adarcias' rootstock, and the lowest on 'GF 677', while no significant differences were found among all the other rootstocks when grafted with 'Tebana'. Differences were also found in the antioxidant contents among rootstocks.
\end{abstract}

\section{INTRODUCTION}

Peach (Prunus persica) is the third most important fruit grown in the world, after apples and pears. Peach production comes mainly from China, Mediterranean area (Italy and Spain) and United States (Faostat, 2007). Breeding programs are active in the release of new genotypes, improving peach adaptability to soil (Moreno et al., 1994; Felipe, 2009) and fruit quality (Monet and Bassi, 2008). More recently, phytochemical 
constituents, such as soluble sugars profile, vitamin $\mathrm{C}$ or antioxidant capacity, have been included in breeding programs as indicators of fruit quality parameters (Cantín et al., 2009a, 2009b). Sugars and flesh firmness are very important parameters for market quality of peaches and are also very appreciated by consumers (Sudebi and Walsh, 2009; Kim et al., 2009). They are also indicators when fruit have reached maturity, when are ready for harvest (Kim et al., 2009), and for assessing the stage of ripening of the fruit. It has been widely demonstrated that rootstocks affect fruit quality and sugars content (Albás et al., 2004; Giorgi et al., 2005; Remorini et al., 2008) and antioxidant capacity of cultivars (Remorini et al., 2008). On the other hand, there is supported evidence that antioxidants compounds (poliphenolics, anthocyanins or flavonoids) reduce the risk of diseases and also have health benefits effects in the prevention of chronic diseases, such as cardiovascular disease and certain types of cancer (Ruiz et al., 2005). Similarly, soluble sugars are well known for contributing to a range of fruit quality traits such as flavour, texture and health properties (Cantín et al., 2009b).

The present work aimed to evaluate the effect of different rootstocks grafted with 'Queen Giant' and 'Tebana' cultivars on yield characteristics, fruit quality and phytochemical parameters when growing in Mediterranean conditions.

\section{MATERIAL AND METHODS}

Six different almond $\mathrm{x}$ peach hybrid rootstocks ('Adafuel', 'Adarcias', 'Cadaman', 'Garnem', 'Felinem' and 'GF 677') were compared in one trial established during the winter of 1998-1999. Rootstocks chosen for this study included six almond peach hybrid selections (Prunus amygdalus x Prunus persica). 'Adafuel' (Cambra, 1990) and 'Adarcias' (Moreno and Cambra, 1994; Moreno et al., 1994) are selections from the Experimental Station of Aula Dei (CSIC). 'Garnem' and 'Felinem' ('Garfi' x 'Nemared') (Felipe et al., 1997; Felipe, 2009) are selections from the Centre of Research and AgroFood Technology of Aragón (CITA-DGA). 'Cadaman' (Edin and Garcin, 1994) is a French-Hungarian co-obtention. 'GF 677' (Bernhard and Grassely, 1981) rootstock was taken as controls. They were grafted with 'Tebana' peach and 'Queen Giant' nectarine cultivars during the summer of 1997. The experiment was performed in the Ebro Valley, at the Experimental Station of Aula Dei-CSIC (Zaragoza, Spain) on a calcareous soil, with $29-30 \%$ total calcium carbonate, $7.4-7.6 \%$ active lime, $\mathrm{pH}$ in water 8.0 and a clayloam texture. Trees were trained to the standard open vase system and planted at a spacing of $6 \mathrm{~m} \times 5 \mathrm{~m}$. Hand thinning was carried out to reduce fruit load when required. Trees were grown under standard conditions of fertilization and pest and disease control. The experiment was established in a randomised block design with five single-tree replications for each scion-stock combination. The trunk cross-sectional area (TCSA) and cumulative yield were calculated. Fruits were harvested by a single person to keep consistency maturity grade. During harvest, 20 mature fruits of each tree were randomly selected. Fruits were peeled and frozen in liquid nitrogen, and kept at $-20{ }^{\circ} \mathrm{C}$ until analysed. Flesh firmness (FF) and soluble solid content (SSC) were measured using a penetrometer (Model FT-327) and a digital refractometer (Atago PR-101), respectively. To analyze titratable acidity (TA), the juice samples were microtitrated with $0.1 \mathrm{~N} \mathrm{NaOH}$, according to A.O.A.C. (1990). Anthocyanins, flavonoids and vitamin C were quantified with a spectrophotometer according to Cantín et al. (2009a). Phenolics were quantified by the Folin-Ciocalteau method (Cevallos-Casals and Cisneros-Zevallos, 2003) and relative antioxidant activity (RAC) by the DPPH radical method (Brand-Williams et al., 1995). Soluble sugars from fruits (sucrose, glucose, fructose and sorbitol) were analyzed by High 
Performance Liquid Chromatography (HPLC, Waters 515, Milford, MA, USA). The means from two replicates were obtained for each single-tree replication and analyzed statistically using SPSS 17.0 (Inc, Chicago, USA). When the F test was significant, means were separated by Duncan's multiple range $(\mathrm{P} \leq 0.05)$. Also, the analyses of bilateral Pearson correlation were carried out to study relationships among parameters.

\section{RESULTS AND DISCUSSION}

Results for 'Tebana' include only 'Adafuel', 'Adarcias', 'Cadaman' and 'GF 677' rootstocks, due to the high mortality of trees on 'Felinem' and 'Garnem'. Tree mortality has been attributed to sensitivity to root asphyxia, because these rootstocks are mostly adapted to irrigation conditions but they require well drained soils (Felipe, 2009). The lowest vigour was induced by 'Adarcias' rootstock with both varieties, although differences were not significant with 'Cadaman' when grafted with 'Queen Giant' (Table 1). The tendency of 'Adarcias' towards lower vigour has been already described (Moreno et al., 1994; Zarrouk et al., 2005). At the eleventh year after grafting, the highest cumulative yield were showed on 'Felinem', and the lowest on 'Adarcias', while no significant differences were found among all the other rootstocks, in the case of 'Queen Giant'. Yield efficiency was higher on 'Cadaman' rootstock, although differences were not significant with 'Felinem' when grafted with 'Queen Giant'. This performance on yield characteristics is in accordance with the results of Albás et al. (2004) and Zarrouk et al. (2005). Despite the tendency of 'Adafuel', 'Garnem', 'Felinem' and 'GF 677' to show the higher cumulative yield, his higher vigour decrease its yield efficiency, as previously reported (Moreno et al., 1994; Zarrouk et al., 2005). On the contrary, 'Cadaman' rootstock induced higher yield efficiency because of its lower vigour and high yield. 'Adafuel' resulted in the largest fruit weight, although no significant differences were found with 'Cadaman', 'Garnem' and 'GF 677' with 'Queen Giant'. Other studies also showed the tendency of 'Adafuel' to produce higher mean fruit weight (Albás et al., 2004; Moreno et al., 1994). For 'Tebana', no significant differences were found among rootstocks.

The fruit quality characteristics were also significantly affected by rootstocks (Table 2). In the case of 'Queen Giant' nectarine, the greatest SSC was recorded on 'Adarcias' and 'Cadaman' and the lowest on 'GF 677'. The same tendency was also found with 'Tebana' cultivar but differences were not significant among rootstocks. The tendency of 'Adarcias' to induce higher SSC was also reported by Albás et al. (2004) grafted with different peach cultivars. Thus, fruits from the less vigorous trees had the highest SSC values, in good agreement with Giorgi et al. (2005). For 'Queen Giant', the highest firmness was induced by 'Cadaman' and the lowest by 'GF 677', whereas no significant differences were found among all the other rootstocks. The highest TA was also induced by 'Cadaman', although this did not differ significantly from 'Adafuel' when grafted with 'Queen Giant'. For 'Tebana', the highest vitamin C content was shown on 'Adarcias' rootstock, and the lowest on 'GF 677', while no significant differences were found with 'Adafuel' and 'Cadaman'. For 'Queen Giant', the highest antioxidant capacity content (RAC) was shown on 'Garnem' and the lowest on 'GF 677', while no significant differences were found among all the other rootstocks. The highest value for all sugar components (sucrose, glucose, fructose and sorbitol) was found on 'Adarcias', although in the case of sucrose for 'Queen Giant' and sorbitol for 'Tebana', no significant differences were found among rootstocks (data not shown). A positive and significant correlation was found between cumulative yield and vigour in 'Queen Giant' $(\mathrm{r}=0.60 ; P$ 
$\leq 0.05)$ and 'Tebana' ( $\mathrm{r}=0.79 ; P \leq 0.05)$ cultivars. In 'Queen Giant', a significant correlation was also found between vigour and $\mathrm{pH}(\mathrm{r}=0.50 ; P \leq 0.05)$ and between fruit weight and flesh firmness $(\mathrm{r}=0.40 ; P \leq 0.05)$. Analyzing phytochemical constituents, the most important correlations were found between phenol content and antioxidant activity. Other correlations, such as antioxidant activity with flavonoid content and phenol content with flavonoid content were also found (data not shown). Also, individual sugar content was positively and highly correlated with each other (data not shown). These results show the important relationship between the characteristics of yield, vigour or fruit weight and the factors of fruit quality and nutritional value.

In conclusion, the less vigorous rootstocks ('Adarcias' and 'Cadaman') seem to induce a better fruit quality to the studied peach cultivars. Our results show the relationship between the characteristics on plant adaptability and development, such as yield, vigour or fruit weight and the factors of fruit quality and nutritional value.

\section{ACKNOWLEDGEMENTS}

We thank R. Giménez and J. Aparicio for technical assistance. This study was funded by the Spanish MICINN (Ministry of Science and Innovation) grants AGL200505533 and AGL-2008-00283, cofunded by FEDER, and the Regional Government of Aragon (A44). C. Font was supported by a JAE fellowship from CSIC (Consejo Superior de Investigaciones Científicas).

\section{Literature cited}

Albás, E. S., Jiménez, S., Aparicio, J., Betrán, J. A. and Moreno, M. A. 2004. Effect of several peach $\mathrm{x}$ almond hybrid rootstocks on fruit quality of peaches. Acta Hort. 658: 321-326.

Bernhard, R. and Grassely, C., 1981. Les pêchers x amandiers. L'Arboriculture Fruitiére 328:37-42.

Brand-Williams, W., Cuvelier, M. E. and Berset, C. 1995. Use of a free-radical method to evaluate antioxidant activity. Lebensm. Wiss. Technol. 28(1):25-30.

Cambra, R., 1990. 'Adafuel' an almond x peach hybrid rootstock. HortScience 25:584.

Cantín, C.M., Moreno, M.A. and Gogorcena, Y. 2009a. Evaluation of the antioxidant capacity, phenolic compounds, and vitamin $\mathrm{C}$ content of different peach and nectarine [Prunus persica (L.) Batsch] breeding progenies. J. Agric. Food. Chem. 57:45864592.

Cantín, C.M., Gogorcena, Y and Moreno, M.A. 2009b. Analysis of phenotypic variation of sugar profile in different peach and nectarine [Prunus persica (L.) Batsch] breeding progenies. J. Sci. Food. Agric. (in press).

Cevallos-Casals, B. A. and Cisneros-Zevallos, L. 2003. Stoichiometric and kinetic studies of phenolic antioxidants from Andean purple corn and red-fleshed sweetpotato. J. Agric. Food Chem. 51(11):3313-3319.

Edin, M. and Garcin, A., 1994. Un nouveau porte greffe du pêcher Cadaman-Avimag. L'Arboriculture Fruitière 475:20-23.

FAOSTAT. 2007. FAOSTAT. http://faostat.fao.org/

Felipe, A.J., Gómez-Aparisi, J., Socías, R. and Carrera, M., 1997. The almond x peach hybrid rootstocks breeding program at Zaragoza (Spain). Acta Hort. 451:259-262.

Felipe, A. J. 2009. 'Felinem', 'Garnem', and 'Monegro' almond x peach hybrid rootstocks. HortScience 44(1):196-197. 
Giorgi, M., Capocasa, F., Scalzo, J., Murri, G., Battino, M. and Mezzetti, B. 2005. The rootstock effects on plant adaptability, production, fruit quality, and nutrition in the peach (cv. 'Suncrest'). Sci. Hort. 107(1):36-42.

Kim, K. B., Lee, S., Kim, M. S. and Cho, B. K. 2009. Determination of apple firmness by nondestructive ultrasonic measurement. Postharvest Biol. Technol. 52(1):44-48.

Monet, R. and Bassi, D. 2008. p.61-84. Classical genetics and breeding. In D.R. Layne and D. Bassi (eds.), The Peach, Botany, Production and Uses.

Moreno, M.A. and Cambra, R., 1994. Adarcias: an almond x peach hybrid rootstock. HortScience 29:925.

Moreno, M. A., Tabuenca, M. C. and Cambra, R. 1994. Performance of Adafuel and Adarcias as peach rootstocks. HortScience 29(11):1271-1273.

Remorini, D., Tavarini, S., Degl'Innocenti, E., Loreti, F., Massai, R. and Guidi, L. 2008. Effect of rootstocks and harvesting time on the nutritional quality of peel and flesh of peach fruits. Food Chem. 110(2):361-367.

Ruiz, D., Egea, J., Gil, M. I. and Tomás-Barberán, F. A. 2005 Characterization and quantitation of phenolic compounds in new apricot (Prunus armeniaca L.) varieties. J. Agric. Food Chem. 53(24):9544-9552.

Subedi, P. P. and Walsh, K. B. 2009. Non-invasive techniques for measurement of fresh fruit firmness. Postharvest Biol. Technol. 51(3):297-304.

Zarrouk, O., Gogorcena, Y., Gómez-Aparisi, J., Betrán, J. A. and Moreno, M.A. 2005. Influence of almond $\mathrm{x}$ peach hybrids rootstocks on flower and leaf mineral concentration, yield and vigour of two peach cultivars. Sci. Hort. 106(4):502-514. 


\section{$\underline{\text { Tables }}$}

Table 1. Yield characteristics of 'Queen Giant' and 'Tebana' cultivars grafted on different rootstocks, in the eleventh year after grafting.

\begin{tabular}{lllcccc}
\hline Cultivar & Rootstock & $\begin{array}{c}\text { TCSA } \\
\left(\mathrm{cm}^{2}\right)\end{array}$ & $\begin{array}{c}\text { Yield } \\
\left(\mathrm{kg} \mathrm{tree}^{-1}\right)\end{array}$ & $\begin{array}{c}\mathrm{CY} \\
\left(\mathrm{kg} \mathrm{tree}^{-1}\right)\end{array}$ & $\begin{array}{c}\text { YE } \\
\left(\mathrm{kg} \mathrm{cm}^{-2}\right)\end{array}$ & $\begin{array}{c}\text { Fruit } \\
\text { weight }(\mathrm{g})\end{array}$ \\
\hline Queen & Adafuel & $185.4 \mathrm{bc}$ & $14.9 \mathrm{ab}$ & $175 \mathrm{~b}$ & $0.95 \mathrm{~b}$ & $227.6 \mathrm{~b}$ \\
Giant & Adarcias & $143.9 \mathrm{a}$ & $7.8 \mathrm{a}$ & $130 \mathrm{a}$ & $0.91 \mathrm{ab}$ & $188.1 \mathrm{a}$ \\
& Cadaman & $171.1 \mathrm{ab}$ & $18.8 \mathrm{~b}$ & $198 \mathrm{bc}$ & $1.16 \mathrm{c}$ & $221.5 \mathrm{ab}$ \\
& Felinem & $214.3 \mathrm{~cd}$ & $23.2 \mathrm{~b}$ & $224 \mathrm{c}$ & $1.04 \mathrm{bc}$ & $192.1 \mathrm{a}$ \\
& Garnem & $228.6 \mathrm{~d}$ & $19.6 \mathrm{~b}$ & $197 \mathrm{bc}$ & $0.87 \mathrm{ab}$ & $209.3 \mathrm{ab}$ \\
& GF 677 & $244.1 \mathrm{~d}$ & $15.7 \mathrm{ab}$ & $178 \mathrm{bc}$ & $0.73 \mathrm{ab}$ & $219.7 \mathrm{ab}$ \\
\hline Tebana & Adafuel & $212.8 \mathrm{~b}$ & $35.5 \mathrm{~b}$ & $202 \mathrm{~b}$ & $0.96 \mathrm{a}$ & $143.4 \mathrm{a}$ \\
& Adarcias & $129.3 \mathrm{a}$ & $11.4 \mathrm{a}$ & $125 \mathrm{a}$ & $0.95 \mathrm{a}$ & $137.9 \mathrm{a}$ \\
& Cadaman & $183.3 \mathrm{~b}$ & $30.9 \mathrm{ab}$ & $240 \mathrm{~b}$ & $1.31 \mathrm{a}$ & $140.3 \mathrm{a}$ \\
& GF 677 & $190.4 \mathrm{~b}$ & $28.4 \mathrm{ab}$ & $197 \mathrm{~b}$ & $1.03 \mathrm{a}$ & $148.3 \mathrm{a}$ \\
\hline
\end{tabular}

Means with the same letter are not significantly different according to $t$ tests $(P \leq 0.05)$. Abbreviations: TCSA, Trunk cross-sectional area; CY, Cumulative yield; YE, yield efficiency.

Table 2. Fruit quality parameters of 'Queen Giant' and 'Tebana' cultivars grafted on different rootstocks, in the eleventh year after grafting.

\begin{tabular}{|c|c|c|c|c|c|c|}
\hline Cultivar & Rootstock & $\begin{array}{c}\text { Firmness } \\
\left(\mathrm{kg} / \mathrm{cm}^{2}\right)\end{array}$ & $\begin{array}{c}\text { SSC } \\
\left({ }^{\circ} \text { Brix }\right)\end{array}$ & $\begin{array}{c}\text { TA } \\
(\mathrm{g} \text { malic } \\
\text { acid } \\
\left.100 \mathrm{~mL}^{-1}\right)\end{array}$ & $\begin{array}{c}\text { Vitamin C } \\
\text { (mg ASA/ } \\
100 \mathrm{~g} \mathrm{FW)}\end{array}$ & $\begin{array}{c}\text { RAC } \\
(\mu \mathrm{g} \text { Trolox/g } \\
\text { FW) }\end{array}$ \\
\hline Queen & Adafuel & $2.5 \mathrm{ab}$ & $11.1 \mathrm{ab}$ & $3.12 \mathrm{ab}$ & $2.6 \mathrm{a}$ & $327.7 \mathrm{ab}$ \\
\hline \multirow{5}{*}{ Giant } & Adarcias & $2.1 \mathrm{ab}$ & $12.6 \mathrm{~b}$ & $3.07 \mathrm{a}$ & $3.3 \mathrm{a}$ & $390.6 \mathrm{ab}$ \\
\hline & Cadaman & $2.7 \mathrm{~b}$ & $12.2 \mathrm{~b}$ & $3.50 \mathrm{~b}$ & $2.7 \mathrm{a}$ & $305.4 \mathrm{ab}$ \\
\hline & Felinem & $1.8 \mathrm{ab}$ & $11.3 \mathrm{ab}$ & $2.90 \mathrm{a}$ & $3.4 \mathrm{a}$ & $336.5 \mathrm{ab}$ \\
\hline & Garnem & $1.7 \mathrm{ab}$ & $11.5 \mathrm{ab}$ & $2.90 \mathrm{a}$ & $3.7 \mathrm{a}$ & $399.2 \mathrm{~b}$ \\
\hline & GF 677 & $1.4 \mathrm{a}$ & $10.7 \mathrm{a}$ & $2.80 \mathrm{a}$ & $3.3 \mathrm{a}$ & $305.4 \mathrm{a}$ \\
\hline \multirow[t]{4}{*}{ Tebana } & Adafuel & $2.2 \mathrm{a}$ & $11.5 \mathrm{a}$ & $1.26 \mathrm{a}$ & $2.5 \mathrm{ab}$ & $334.1 \mathrm{a}$ \\
\hline & Adarcias & $1.9 \mathrm{a}$ & $12.3 \mathrm{a}$ & $1.35 \mathrm{a}$ & $3.2 \mathrm{~b}$ & $343.7 \mathrm{a}$ \\
\hline & Cadaman & $1.7 \mathrm{a}$ & $12.0 \mathrm{a}$ & $1.30 \mathrm{a}$ & $2.1 \mathrm{ab}$ & $417.3 \mathrm{a}$ \\
\hline & GF 677 & $2.6 \mathrm{a}$ & $11.6 \mathrm{a}$ & $1.41 \mathrm{a}$ & $1.8 \mathrm{a}$ & $299.7 \mathrm{a}$ \\
\hline
\end{tabular}

Means with the same letter are not significantly different according to $t$ tests $(P \leq 0.05)$. Abbreviations: SSC, soluble solid content; TA, titratable acidity; ASA, ascorbic acid; $\mathrm{RAC}$, relative antioxidant capacity. 